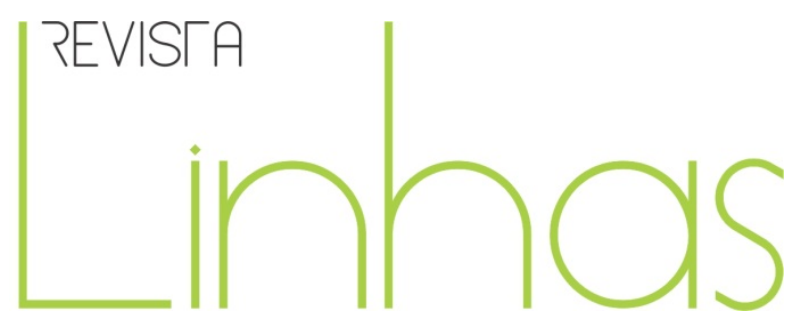

\title{
O discurso das políticas de educação especial na revista Nova Escola
}

\section{Resumo}

Neste trabalho, temos por objetivo analisar a disseminação das políticas de educação especial nas publicações da revista Nova Escola. Para tanto, selecionamos as publicações da revista de 1997 a 2012, que tratavam da inclusão de alunos com necessidades educacionais especiais na escola regular. Após a seleção, tabulamos os artigos para iniciar a análise. A partir dos preceitos da análise de discurso, tendo por base Orlandi (2003), voltamo-nos para a disseminação do discurso político através do conteúdo textual e imagético das reportagens. Os resultados nos mostram que a revista Nova Escola tem feito a disseminação das políticas públicas de educação especial, expressando as mesmas lacunas que encontramos nas políticas inclusivas. $\mathrm{E}$ essas lacunas mostram-se numa inclusão que privilegia o estar na escola apenas para interagir, em detrimento da aprendizagem, secundarizando, assim, a ação pedagógica. Ao tratar da pessoa com deficiência, faz isso muitas vezes utilizando-se dos estereótipos relacionados à deficiência como os de vítima e herói. A inclusão é disseminada como um benefício que é dado para esses indivíduos e não como um direito propriamente dito.

Palavras-chave: Políticas públicas; Necessidades educacionais especiais; Revista Nova Escola; Análise do discurso.
Silvia Márcia Ferreira Meletti

Doutora em Psicologia Escolar e do Desenvolvimento Humano pela Universidade de São Paulo USP - Brasil smeletti@gmail.com

\section{Michelle Mayara Praxedes Silva}

Mestre em Educação pela Universidade Estadual de Londrina - UEL - Brasil mmpraxedes_silva@hotmail.com

\section{Para citar este artigo:}

MELETTI, Silvia Márcia Ferreira; SILVA, Michelle Mayara Praxedes. O discurso das políticas de educação especial na revista Nova Escola. Revista Linhas. Florianópolis, v. 16, n. 31, p. 144 - 172, maio/ago. 2015. 


\title{
The speech of special education policies in Nova Escola magazine
}

\begin{abstract}
We did this work aimed to analise the sowing public policies of especial education within Nova Escola magazine. So, we selected some publications between the year of 2007 and the year of 2012, that dealed with the students especial necessities in regular schools. After it, we chard the dadas to start the analysis. As from the Speech analysis principles, based on Orlandi (2003) we back to the sowing of politic speech through the images and textual reports. Thus, the results showed us that this magazine has done the sowing of public policies of especial education, expressing the same hole find in inclusive policies. This hole shows a inclusion that focus only to go to the school to socialize, forgeting the learning issues, there are an apart in pedagogical action. It is common stereotype disabled people as a victim or as a hero. Inclusion is showing as a given benefit to disabled people, but it is a right.
\end{abstract}

Keywords: Public policies; Special necessities to education; New School magazine; Speech analysis. 


\section{Introdução}

Atualmente, um dos assuntos mais discutidos na educação se refere à educação e à inclusão de pessoas com necessidades educacionais especiais na rede regular de ensino. Sob a influência de acordos realizados junto aos organismos internacionais, o Brasil, a partir da década de 1990, tem estruturado suas políticas educacionais de modo a contemplar as necessidades educacionais de todos os alunos. Essas ações políticas foram pensadas a partir de um discurso, o qual defende que a inclusão de todos na escola rompe com a condição de exclusão imposta ao indivíduo até o momento.

Garcia (2006) nos indica que, no Brasil, a elaboração das políticas educacionais, voltadas à inclusão, ocorreu na reforma educacional ocorrida em 1990, tendo por base as indicações de organismos multilaterais, a fim de inserir o país na economia mundial e garantir financiamentos.

$\mathrm{Na}$ atualidade, o conceito de inclusão tem sido criticado sob várias perspectivas, sendo utilizado em diversas áreas do conhecimento, nos mostrando ser um conceito abstrato. É um conceito recente que tem "uma ênfase própria na área da educação e educação especial" e quando é utilizado pelas políticas "aparece acompanhado de uma aura de inovação e revolução, até mesmo como um novo paradigma social" (GARCIA, 2004, p. 24).

No presente trabalho, o conceito de inclusão é compreendido como sendo parte de um sistema capitalista, que fundamentalmente exclui indivíduos de sua participação plena na sociedade e, como forma de camuflar essa exclusão, cria formas de incluir esses sujeitos. Assim, partimos do pressuposto que estamos num sistema capitalista, no qual a inclusão tem sido tratada como oposto de exclusão e falar sobre exclusão é abordar uma das características do próprio sistema que apresenta em sua essência uma realidade contraditória.

A inclusão, nas políticas atuais, vem sendo entendida como uma resposta à exclusão. A partir de Martins (2002), compreendemos que inclusão e exclusão, no atual sistema econômico, compõem a mesma trama. O sistema capitalista perpetua a exclusão que ele mesmo produz e depende dessa exclusão para existir, assim "a sociedade que exclui é a mesma sociedade que integra e cria formas também desumanas de participação, na medida em que delas faz condição de privilégios e não de direitos" 
(MARTINS, 2002, p. 11). E essas formas de participação são expressas através das políticas públicas, a partir do discurso de inclusão em vários setores, inclusive na área educacional, tendo sempre por base que a inclusão superará a exclusão.

Garcia (2004) nos mostra que o conceito de inclusão tem sido utilizado nas políticas como revolucionário e inovador, mostrando-se como a solução para a exclusão social. A mesma autora, ainda afirma que existem dois posicionamentos teóricos diferentes a respeito da inclusão: um, dos que acreditam e defendem a inclusão como a solução para os problemas sociais, denominados exclusão; o outro, dos que percebem a inclusão e a exclusão como processos da mesma realidade.

A discussão a respeito da inclusão volta-se com grande ênfase à população com necessidades educacionais especiais, a qual se refere aos alunos com deficiência, transtornos globais de desenvolvimento e superdotação/altas habilidades. Conforme dito anteriormente, as formas criadas para incluir essa população são formas desumanas, limitadas. Em relação a essa estruturação, Leher (2009, p. 234) aponta que "o grosso da ação inclusiva é local, pontual, modesta", pois não se investe em políticas sociais, mas em programas que camuflam o real problema, apenas o suavizam.

Partimos do entendimento que o fenômeno da deficiência possui múltiplas facetas, sendo constituído não só por suas características biológicas, como também sociais, históricas e culturais. Consideramos que a deficiência é um fenômeno multifacetado e multideterminado, que além das alterações e consequentes limitações biológicas, é uma condição socialmente construída, situada e significada. A nossa perspectiva parte da teoria Vygotskiniana, na qual as formas de lidar com a pessoa com deficiência têm ligação com o meio social no qual ela está inserida e nos sentidos atribuídos a essa condição.

O contexto histórico cultural de cada sociedade e as nossas experiências de vida nos indicam quem são os considerados diferentes. Quando abordamos o assunto a respeito da deficiência, podemos dizer que estes se afastam de modo preponderante do que é considerado ideal, percebemos que os conflitos são frequentes no relacionamento com seus pares. Ao trabalhar com a deficiência, Amaral (1995) conceitua que estamos diante de uma diferença significativa, que pensando nas relações humanas que são 
estabelecidas com estes indivíduos, o que impera é um clima de conflitos com consequências sociais.

Quando estamos frente a uma fonte de ameaça ou perigo, algo que nos é estranho, nos causa ansiedade e tensão mais especificamente, neste caso, diante da diferença significativa, acionamos mecanismos de defesa. Esse conceito utilizado por Amaral (1995, p. 14), o qual foi criado por Freud, faz referência às "estratégias utilizadas pela pessoa para manutenção do equilíbrio intrapsíquico através da eliminação de uma fonte de segurança, perigo, tensão ou ansiedade". São duas formas possíveis de reação, 0 ataque e a fuga.

Em se tratando da deficiência, a fuga do problema é frequente e "a rejeição pode ser pensada como tendo lugar de destaque, com seu cortejo: abandono, superproteção, negação (AMARAL, 1995, p. 115)". Nesses mecanismos de rejeição, o abandono pode acontecer de forma literal ou de modo implícito, indireto. A superproteção coloca em destaque o protetor, deixando de lado o protegido.

O mecanismo de defesa que enfatizaremos é o da negação; ele se materializa em pessoas que apresentam algum estigma, como os sujeitos com deficiência de três formas, a atenuação, a compensação e a simulação. Esse mecanismo de defesa é expresso por meio de falas diárias às pessoas nessa condição, como uma forma de aliviar a situação em que se encontra a pessoa com deficiência. Na compensação a palavra-chave é o "mas", tentando de alguma forma compensar o estigma por outra qualidade, soltamos colocações como: "é negro, mas tem alma de branco"; ou então tentamos tranquilizar a pessoa atenuando a sua condição: "não é tão grave assim"; outra forma é simular negando totalmente a condição: “é cego, mas é como se não fosse” (AMARAL, 1998, p. 20). As três formas negam a condição do significativamente diferente. Contudo, ainda de acordo com Amaral (1998, p. 20) “enfiar a cabeça na areia não nos liberta da armadilha relacional (continuamos sofrendo a ansiedade na relação interpessoal), nem facilita a vida do significativamente diferente".

Concordantemente, não tratamos as pessoas nessas condições a partir de suas características singulares, mas a partir de estereótipos acoplados à deficiência. 0 estereótipo é entendido como "um julgamento qualitativo, baseado no preconceito e, portanto, anterior a uma experiência” (AMARAL, 1995, p. 120). 
Temos alguns estereótipos utilizados com frequência na mídia, na literatura, nos meios de comunicação em geral, que são os da pessoa com deficiência ser a heroína, a vítima ou a vilã. O uso desses estereótipos é frequente não só às pessoas com deficiência, mas também às pessoas com diferenças significativas de um modo geral (AMARAL, 1998).

A leitura social feita deste indivíduo coloca o sujeito em grande desvantagem social, pois é depreciativa, desencadeando assim interações conflituosas. Vygotsky (1989, apud GOÉS, 2002), em seus estudos, nos leva a conhecer a influência que as relações sociais têm para com o desenvolvimento da pessoa com deficiência.

Vygotsky (1989), ao estudar como se davam os processos educativos de crianças com alguma deficiência ou incapacidade considera que a deficiência tem um significado social, que pode ser mudado conforme as experiências sociais ocorridas no desenvolvimento desse indivíduo. Para tanto, os objetivos da educação dessas pessoas não podem ser diferentes dos demais, é preciso investir em outros meios que não tenham por foco o que a deficiência prejudica, mas que haja um investimento em funções mais complexas, até mesmo intactas.

Destarte, percebe-se que a mudança deve ocorrer na mentalidade da sociedade e, na atual conjuntura, o foco se volta para a inclusão desses sujeitos em vários setores da sociedade, com destaque à inclusão na rede regular de ensino.

\section{A pessoa com deficiência no Brasil}

No Brasil, o atendimento às pessoas com deficiência ficou destinado historicamente à educação especial e esta, por sua vez, constituiu-se de forma paralela ao sistema de ensino. O poder público sempre se mostrou pouco atuante, dando abertura para que as instituições privadas dominassem esse campo. Para tanto, a Constituiç̧ão de 1946 e de 1988 asseguram essa relação público/privado com repasse financeiro e isenção de impostos (MELETTI, 2010). Jannuzzi (2006) afirma que esta relação público/privado é tão intensa como uma "parcial simbiose", a fim de que as políticas públicas sejam influenciadas pelo setor privado. 
A adesão a acordos internacionais, a partir da década de 1990, trouxe mudanças significativas na legislação e, em aspectos gerais, às formas de lidar com as pessoas com necessidades educacionais especiais, incluindo as pessoas com deficiências.

Damos início ao discurso inclusivo nos aparatos legais brasileiros. Já supracitamos os desdobramentos do discurso inclusão/exclusão do qual estamos falando. Essa adesão desdobrou-se em diversas leis, das quais destacamos a LDBEN 9394/96, as Diretrizes Nacionais para a Educação Especial CNE/2001 e, em 2008, a Política Nacional da Educação Especial na Perspectiva da Educação Inclusiva.

Com a lei 9.394/96, a educação especial passa a ser instituída como uma modalidade de ensino. É utilizado pela primeira vez o termo "necessidades educacionais especiais", citado na Declaração de Salamanca (1994) dois anos antes. Percebe-se um avanço no atendimento à pessoa com deficiência:

A Lei n. 9394/96, que estabeleceu as Diretrizes e Bases da Educação Nacional, em seu Artigo 59, determina que os sistemas de ensino assegurarão aos educandos com necessidades especiais, entre outros aspectos: currículos, métodos, técnicas, recursos educativos e organização específicos, para atender às suas necessidades, bem como terminalidade específica para aqueles que não puderem atingir o nível exigido para a conclusão do ensino fundamental, em virtude de suas deficiências. (MELETTI; BUENO, 2011, p. 2)

A respectiva legislação avança no sentido de ampliar e melhorar o atendimento à pessoa com deficiência, contudo não caracteriza claramente quem é o aluno com necessidade educacional especial, dando abertura para um atendimento incerto e impreciso.

Com as Diretrizes de 2001 (BRASIL, 2001), temos a definição da educação especial como uma modalidade de ensino e há a delimitação também de quem é o alunado da educação especial. O termo necessidade educacional especial passa a ser utilizado de forma que amplia essa população alvo, incluindo alunos com deficiência, como também os alunos com dificuldades de aprendizagem. Com essa imprecisão, a incidência de ocorrer uma caracterização indevida é grande. Bueno (2008) afirma que estes termos apresentam muitas imprecisões e ambiguidades. 
Garcia (2004), quando analisa as Diretrizes de 2001, traz-nos uma contribuição a respeito da flexibilização curricular mostrada com grande frequência na legislação. Quanto ao currículo da escola regular, fica estabelecido no artigo 17:

\begin{abstract}
Em consonância com os princípios da educação inclusiva, as escolas das redes regulares de educação profissional, públicas e privadas, devem atender alunos que apresentem necessidades educacionais especiais, mediante a promoção das condições de acessibilidade, a capacitação de recursos humanos, a flexibilização e adaptação do currículo e o encaminhamento para o trabalho, contando, pata tal, com a colaboração do setor responsável pela educação especial do respectivo sistema de ensino. (GARCIA, 2004, p. 5)
\end{abstract}

Desta feita, a escola, ao elaborar seu currículo, tem de fazê-lo de modo flexível e adaptado conforme as condições que o alunado exigir. O uso desta flexibilização curricular expressa diversos sentidos:

[...] a qual pode ter conotações de se contrapor a uma escola seriada, rígida em suas estruturas e "enciclopédias", ou de ser contra desempenhos massificados dos alunos, mas que também pode ser lida como incentivo à redução dos conteúdos a serem apreendidos, conforme as condições individuais dos alunos com necessidades educacionais especiais. (GARCIA, 2004, p. 172)

O que se observa nesse percurso histórico e político é que, partindo do pressuposto de que a sociedade em que vivemos é excludente em sua essência, as políticas acabam mostrando-se limitadas para o que elas se destinam, que é acabar com a exclusão desses sujeitos.

Já na Política Nacional de Educação Especial na Perspectiva da Educação Inclusiva (BRASIL, 2008), percebeu-se que a proposta é incluir a educação especial às propostas do ensino regular. Uma caracterização do aluno com deficiência é feita, deixando mais delimitada a população alvo, retira-se as dificuldades de aprendizagem, restringindo a população alvo da educação especial aos alunos com deficiência. A educação especial é definida "como apoio às necessidades do alunado classificado como população alvo e não de modo amplo como a responsável pela implementação da escola inclusiva" 
(MELETTI, 2010, p. 15). Entretanto, apesar dos avanços nessa política, Bueno e Meletti (2011, p. 163) afirmam que esse documento não tem o mesmo caráter dos anteriores, podendo ser ou não seguido por tratar-se de "uma proposição de governo e não de estado".

Podemos destacar que a atual política do país volta-se para a inclusão das pessoas com deficiência na rede regular de ensino, entendendo essa inclusão como uma maneira de superar as formas de exclusão as quais essas pessoas foram expostas até o momento. Lembrando também que, no nosso entendimento, a inclusão da forma como está estruturada não passa de um discurso politicamente correto, pois conforme Meletti (2006), inclusão e exclusão fazem parte da mesma trama; o sistema depende da existência da exclusão que ele mesmo cria para sua própria manutenção. O discurso oficial divulgado nas políticas públicas volta-se para as necessidades educacionais especiais, a inclusão e a educação especial como uma modalidade de ensino.

Estes discursos, por fazerem parte das políticas públicas, apresentam grande veiculação no meio educacional. Neste estudo, entendemos por discurso o "efeito de sentidos entre locutores" (ORLANDI, 2003, p. 21), mais especificamente, o discurso vai além da fala e da língua, faz referência à significação que os sujeitos realizam daquilo que foi dito. A política é um dos locais em que este discurso é disseminado e esta, por sua vez, tem sua disseminação em diversas instâncias. Dentre essas instâncias, destaca-se grande incidência na escola, em dados oficiais, em produções acadêmicas, nas próprias políticas, dentre outros. Essa disseminação da política de inclusão também pode ser percebida em meios não acadêmicos, que também são utilizados pelos professores.

Neste trabalho, voltaremos nossa atenção para o discurso presente na disseminação dessas políticas, em meios não acadêmicos frequentes no meio educacional, mais especificamente, na revista Nova Escola.

\section{A revista}

Recursos midiáticos são amplamente utilizados pelo professor para se atualizar e realizar sua prática profissional, "entre esses recursos e materiais, uma das referências constantes dos professores tem sido as revistas de ampla divulgação, inclusive 
disponíveis em bancas de jornais (SMOLKA; GENTIL, 2004, p. 194)”. Pensando nessa ampla divulgação, dentre as diversas publicações não acadêmicas no meio educacional, optamos pela revista Nova Escola.

A revista Nova Escola é produzida pelo Grupo Abril e mantida pela Fundação Victor Civita desde sua fundação no ano de 1985. Sua primeira edição foi no ano de 1986 . Seu lançamento entra em consonância com um período de mudanças no país, em que a democratização da educação é um dos princípios dos governantes, assim:

Nesse momento de redemocratização do país é lançado o primeiro número da revista 'Nova Escola, com o discurso de que a 'educação para todos' poderia ser a solução para os problemas nacionais. Por isso, era preciso 'informar', 'apoiar' e 'atualizar' o professor brasileiro. E a revista 'Nova Escola' se disponibilizava a ser o suporte desta informação, veiculando seus ideais de educação, de professor, de alunos, de escola e de sociedade. (RIPA, 2010, p. 106)

A revista volta-se para assuntos em torno do cotidiano escolar divulgando-os em forma de "entrevistas com especialistas, artigos, relatos de experiências, reportagens sobre diversos assuntos temáticos, projetos que tiveram bons resultados, biografia de pensadores, indicações de eventos, etc.” (RIPA, 2010, p. 14). Além dos exemplares impressos, a revista Nova Escola também conta com um site que apresenta diversos recursos como: planos de aula da educação infantil ao ensino médio, vídeos educativos, jogos, notícias, dentre outros recursos. Através do site é possível encontrar as edições dos últimos sete anos da revista, como também todas as suas edições especiais.

Essa publicação, em parceria com o governo federal, durante o governo de Fernando Henrique Cardoso, passa a utilizar-se do FNDE (Fundo Nacional de Desenvolvimento da Educação) para pagar a sua distribuição gratuita nas escolas brasileiras (SILVA; FEITOSA, 2008). Tendo uma distribuição mensal gratuita que chega a 700 mil exemplares, assim estamos nos referindo "ao único periódico educacional ao qual a maioria dos professores da rede pública tem acesso" (BUENO, 2007, p. 303).

Silva e Feitosa (2008) destacam que ela se apresenta como uma revista hegemônica no campo das revistas pedagógicas e repercutiu os acontecimentos do 
governo Fernando Henrique Cardoso, legitimando essas propostas. Em consonância com a Reforma Educacional do governo FHC, a revista muda sua estrutura e o enfoque de suas publicações, mostrando claramente sua aderência às propostas da Reforma. Passa a utilizar os termos multidisciplinaridade, interdisciplinaridade e temas transversais como temática de suas seções (SILVA; FEITOSA, 2008). O que mais se destaca na

[...] demonstração do alinhamento da RNE com a implantação da Reforma Educacional foi a veiculação, a partir de 1998, de um suplemento intitulado 'PCN Fáceis de Entender' para explicar aos Professores, de forma objetiva e incluindo sugestões práticas, os Parâmetros Curriculares Nacionais, então recém-lançados pelo Ministério da Educação. (SILVA; FEITOSA, 2008, p. 187)

Houve uma grande divulgação dos PCNs pela revista, contudo nenhuma crítica foi lançada ou sequer um espaço para a mesma ser realizada pelos seus leitores.

A revista possui as mesmas características das demais publicações do Grupo Abril, com capas atraentes, cheia de cores, há grande popularização em seus conteúdos, além de sempre trazer alunos e professores felizes e sorridentes "um pressuposto básico é exaustivamente repetido: os problemas educacionais sempre podem ser resolvidos, bastando que para isso cada um faça a sua parte" (BUENO, 2007, p. 303). Outra característica é que:

A revista traz um grande número de fotos de pessoas, protagonistas e autores dos textos, bem como fotos de locais ou situações escolares. Isso aponta para uma função que vai além da ilustração: as fotos entram na composição do texto escrito, produzindo, com isso, um efeito de evidência. Esse efeito emerge da relação entre essa forma de ilustração e o tipo de texto que caracteriza a revista: a reportagem. Ou seja, dado que na reportagem, como discurso jornalístico, privilegia-se a objetividade, a fotografia tende a exibir o fato e a comprovar a existência da pessoa que fala, que escreve, que depõe. (SMOLKA; GENTIL, 2004, p. 196)

Segundo Matos (2008), o objetivo da revista é voltado para a informação e a acessibilidade, pois ela foca na venda a preço de custo e no fato de que para o professor 
desenvolver bem as suas tarefas, precisa ser bem informado. O tom utilizado é sempre o do marketing e a linguagem é jornalística.

\section{Método}

A nossa análise tem por base a Análise do Discurso, que é constituída por três áreas do conhecimento, sendo elas, o Marxismo, a Psicanálise e a Linguística. A partir da convergência dessas áreas, tem o discurso como seu objeto de estudo, sendo o discurso "efeito de sentidos entre locutores" (ORLANDI, 2003, p. 21). Existe um cuidado em não confundir discurso com apenas transmissão de informação ou com a fala, pois, "o discurso tem sua regularidade, tem seu funcionamento que é possível apreender se não opomos o social e o histórico, o sistema e a realização, o subjetivo ao objetivo, o processo ao produto" (ORLANDI, 2003, p. 22). Nesse entendimento, compreendermos que o discurso:

[...] não se trata de transmissão de informação apenas, pois, no funcionamento da linguagem, que põe em relação sujeitos e sentidos afetados pela língua e pela história, temos um complexo processo na constituição desses sujeitos e produção de sentidos e não meramente transmissão de informação. (ORLANDI, 2003, p. 21)

Para realizar a análise do discurso, cria-se um dispositivo teórico que permite não só a interpretação, mas a compreensão deste objeto simbólico, pois "quando se interpreta já se está preso em um sentido. A compreensão procura a explicitação dos processos de significação presentes no texto" (ORLANDI, 2003, p. 26).

Para compreender e encontrar esses sentidos do discurso, a memória torna-se nossa aliada como sendo um interdiscurso, "este é definido como aquilo que fala antes, em outro lugar, independente" (ORLANDI, 2003, p. 31). O que já foi dito, tem relação com o que se está dizendo naquele momento. Essa relação nos mostra o quanto a história e a ideologia inserem-se no nosso dizer. 
Neste trabalho, entendemos que o discurso é composto por todos esses componentes explicitados por Orlandi (2003), acrescentando-se a isto a condição indicada por Bakhtin (2002), de que a palavra compõe o discurso. Neste entendimento, aquilo que foi silenciado, a história, a memória e, consequentemente, a ideologia, fazem parte deste discurso.

A nossa reflexão faz-se pertinente para que percebamos como a linguagem tem relação com a sua exterioridade (ORLANDI, 2003). Mais do que isto, cabe ao analista do discurso a "compreensão de como um objeto simbólico produz sentidos, como ele está investido de significância para e por sujeitos" (ORLANDI, 2003, p. 26). A revista Nova Escola, desta maneira, é compreendida como um instrumento de registro da palavra, do discurso; cabe-nos a função de entender como a revista significa tanto no seu conteúdo textual quanto imagético, no que tange a disseminação das políticas públicas educacionais, pois do mesmo modo que ela é uma expressão da política é também um meio de divulgação.

\section{Procedimentos da pesquisa}

O período selecionado para analisar as revistas é de janeiro de 1997 a dezembro de 2012. O ano de 1997 para início é escolhido por ser o ano pós LDB, partindo do princípio que a lei 9391/96 é um marco na educação especial. E o ano de 2012, por ser o ano de início da pesquisa de dissertação. A revista tem 10 publicações por ano, uma a cada mês, com exceção dos meses de férias escolares. Assim, pelo período escolhido, tivemos um total de 160 revistas para realizar a seleção dos artigos.

Para acessar as publicações, utilizamos o acervo de periódicos da biblioteca central da Universidade Estadual de Londrina (UEL), a qual possui um acervo praticamente completo das publicações da Revista Nova Escola. Os números que não foram encontrados na biblioteca da UEL, foram encontrados na Biblioteca Pública do município de Londrina, assim, conseguimos contemplar todos os números dentro do período selecionado. 
A nossa investigação fundamentou-se, inicialmente, a partir de três eixos: conceito de inclusão, de educação especial e da população alvo. A escolha destes temas justifica-se no fato de ser o fio condutor nas discussões das políticas públicas de educação especial.

A primeira etapa da pesquisa foi descritiva. Tendo por pressuposto que a escolha dos artigos a serem lidos em uma revista dá-se por meio do título, fizemos a seleção prévia a partir dos sumários. Para serem selecionados, os artigos teriam que ter em seu título alguma indicação que se voltasse para a temática dos eixos de análise. Quando havia alguma dúvida no título, uma rápida leitura do artigo era realizada.

Nesta seleção, contabilizamos um total de 29 artigos e duas revistas no formato de edição especial voltados para a temática de inclusão. Após esta seleção, fizemos uma leitura descritiva de cada artigo selecionado para realizar sua caracterização indicando: ano de publicação, autor, tema, deficiência ou necessidade educacional especial, tipo de artigo, número da revista, dentre outras informações que fossem necessárias, como por exemplo, se era ou não reportagem de capa.

Após esta organização dos dados, passamos para a análise em si, em que buscamos nos artigos, através dos preceitos da Análise de Discurso, a disseminação das políticas públicas por meio dos eixos temáticos já citados.

\section{Resultados}

Para dar início a nossa análise, é importante retomar que no trabalho com documentos e na análise do discurso precisamos estar alertas, em estado de reflexão. Temos que nos atentar não só aos textos, mas também às imagens ou qualquer outro detalhe que nos permita apreender este discurso, que neste estudo trata da disseminação das políticas de educação especial.

Como já citado, a revista Nova Escola durante governos anteriores, pode mostrar o poder ideológico que ela tem em perpetuar as propostas educacionais do governo em questão. Fez isso através da divulgação dos PCNs (Parâmetros Curriculares Nacionais) e, como consequência dessa aderência ao plano do governo, alterou as temáticas dos seus artigos, mudando o enfoque. 
Tendo por base os preceitos da análise do discurso, a nossa análise voltar-se-á para: texto, imagens e legendas, nos quais distinguiremos o texto da reportagem do texto das legendas das imagens. O nosso entendimento é de que todas as dimensões da reportagem são expressões discursivas, por isso a análise textual e imagética são pertinentes. Apresentaremos nossos dados em dois eixos de análise: situações de ensino e interações no interior da escola.

\section{SITUAÇÕES DE ENSINO}

Neste eixo, denominamos como situações de ensino às referências feitas na revista à escolarização formal, mais especificamente, às situações de ensino de conteúdo curriculares.

Em uma reportagem de capa intitulada "Inclusão: qualidade para todos", temos o trabalho desenvolvido por uma escola particular, Escola Viva, que tem vários alunos com deficiência. Selecionamos nesta reportagem a história de um aluno que é relatada em um box da seguinte forma:

Tamanho é documento

Rui Lellot, 16 anos, também nasceu com Síndrome de Down. Ele estuda na mesma escola de Marina, mas apresenta dificuldades de aprendizagem muito maiores. Está sendo alfabetizado, mas ainda assim cursa a $7^{\mathrm{a}}$ série. 'Já imaginou um menino do tamanho dele na $1^{\mathrm{a}}$ série?', questiona Sônia Dreyfuss. 'Sem dúvida, já teria desistido de estudar e estaria trancado em casa', estima. 'Rui tem muitas dificuldades; não consegue interpretar ou escrever um texto, mas fica lá com todo mundo. Sempre peço a opinião dele e estimulo sua participação, mesmo que seja apenas social. Não posso enxergá-lo como uma criança', diz a professora Liliana Cecilia Carvalho. Apesar de muito tímido, ele entende quase tudo que lhe pedem. Muitas vezes ele é o primeiro a responder a uma pergunta na classe, desde que sejam coisas corriqueiras, como o dia da semana, a estação do ano, que aluno faltou. Ele é muito atento. Seu problema é o conteúdo das matérias: o Rui não vai além do que já conseguiu na $1^{\text {a }}$ série, acrescenta. (JOVER, 1999, p. 13)

Iniciemos nossa crítica mostrando que este aluno apresenta várias dificuldades em seu processo de escolarização, entretanto não há nenhuma crítica por parte da revista a respeito dessas dificuldades. Estar lá com todo mundo e ter amigos é o mais importante a 
ser destacado. Ao analisarmos este trecho, percebemos o descompasso que há no ensino que é dado aos alunos com deficiência e o que é ofertado aos demais alunos. No caso de Rui, percebe-se que há uma relevância na interação dele com os demais, em detrimento de sua aprendizagem. Nota-se, nesse caso, a questão da progressão à revelia da aprendizagem, devido à discrepância que há na idade de Rui, 16 anos, e a série em que se encontra - $7^{\text {a }}$ série; se comparada à idade que ele possui, já deveria estar no último ano do ensino médio.

Em outra reportagem intitulada "Mente Estimulada" (RODRIGUES, 2009), que aborda a questão de como estimular alunos com deficiência intelectual, depois de a revista trazer dicas do trabalho com estes alunos encontramos o caso de Moisés:

Foi o que fez a professora Marina Fazio Simão, da EMEF Professor Henrique Pegado, na capital paulista, para conseguir a atenção de Moisés de Oliveira, aluno com síndrome de Down da $3^{\text {a }}$ série. "Ele não ficava parado assistindo a aula", lembra ela. Este ano, em um projeto sobre fábulas, os avanços começaram a aparecer. "Nós lemos para a sala e os alunos recontam a história de maneiras diferentes. No caso dele, o primeiro passo foram os desenhos. Depois, escrevi com ele o nome dos personagens e palavras-chave", relata ela.

Na legenda da imagem de Moisés temos o seguinte: "Concentração: enquanto a turma lê fábulas, Moisés faz desenhos sobre o tema para exercitar o foco (RODRIGUES, 2009, p. 92). Assim, temos mais uma vez explícita a distância das atividades dos alunos com deficiência. Ao analisarmos o texto da reportagem, longe de julgar o trabalho desenvolvido pela professora, que não é o nosso objetivo, percebemos que a professora descreveu claramente como seu trabalho foi desenvolvido e seus objetivos para com este aluno. Entretanto, o destaque dado à revista mostra uma divergência entre o que foi mostrado na imagem e o texto escrito. Se nos determos apenas à imagem que está em destaque, pois ocupa metade de uma página, notamos o aluno num ensino individualizado, que conforme a legenda estaria fazendo uma coisa totalmente diferente do restante da turma.

Essa questão do ensino diferente do restante da turma pode ser percebida em outro artigo, o qual também trata sobre deficiência intelectual, cujo título é "Cada um 
aprende de um jeito" (CAVALCANTE, 2006). No subtítulo do tema da reportagem, temos o seguinte: "Professores propõem a alunos de $1^{\mathrm{a}}$ a $8^{\mathrm{a}}$ série com deficiência as mesmas atividades planejadas para os demais" (CAVALCANTE, 2006, p. 44). Contudo, no texto do artigo encontramos a história de Diogo:

O simples fato de ter o material já ensina. Certa vez, Diogo Mitsuro Nakagawa, 15 anos, aluno da 8 a série, disse a Rossana Ramos, diretora da escola: 'Amanhã é sábado e eu vou passear com meu pai'. A diretora perguntou como ele sabia que o dia seguinte seria um sábado. Ele respondeu: 'Porque hoje teve apostila da sociologia. Então hoje é sextafeira'. Segundo Rossana, ter um material que estabelece a rotina da escola deu a esse aluno a noção de tempo. 'Essa foi a aprendizagem dele naquele momento'. (CAVALCANTE, 2006, p. 44)

O aprendizado destacado no relato sobre a temporalidade é de extrema relevância, contudo, se levarmos em consideração que o aluno está na $8^{\mathrm{a}}$ série, perceberemos o que Garcia (2004) chama de "hierarquização dos conteúdos", e nessa hierarquia, os conteúdos destinados ao aluno com deficiência são conteúdos préescolares. A apostila de sociologia não é usada para que ele aprenda o conteúdo de sociologia, assim como os demais, mas como um recurso para que ele aprenda a temporalidade. Garcia (2004) tece algumas críticas à fragmentação e redução dos conteúdos para as pessoas com deficiência apresentadas nas políticas. A autora salienta que as políticas não se preocupam em mostrar a importância e os modos como os alunos com deficiência aprenderão os conteúdos. Ao contrário disso, ela aborda meios legais de permitir que este conteúdo seja minimizado.

A referência está colocada nas condições individuais do aluno para entrar em contato com o currículo. Logo, as necessidades especiais estão sendo compreendidas não como estratégias alternativas e criativas que possam ser propostas aos processos de ensinar e aprender, mas como o conjunto de condições que o aluno apresenta. Ou seja, ainda que de maneira descritiva trata-se de um diagnóstico seguido de um prognóstico curricular, uma vez que 'conteúdos básicos' permanecem ou são eliminados segundo as 'diferenças individuais'. (GARCIA, 2004, p. 172) 
Através da noção de flexibilização curricular, eliminação de conteúdos do currículo e também "eliminação de objetivos básicos - quando extrapolam as condições do aluno para atingi-lo temporária ou permanentemente" (Brasil, 1998, p. 39). Existe, assim, uma hierarquia nos conteúdos, aos conteúdos que são para os alunos com deficiência e o que deve ser ensinado para os demais alunos (GARCIA, 2004).

Meletti (2006), em sua tese sobre as instituições especiais, nos mostra que essa questão da infantilização da pessoa com deficiência intelectual é muito frequente nas instituições especiais, dado que:

Destaca-se a ênfase na utilização de parâmetros curriculares da educação infantil (o a 6 anos) como referência inclusive para os alunos dos níveis escolares (7 a 16 anos); a utilização de atividades pré-escolares tendo por base mais o nível cognitivo do que a faixa etária do aluno; a referência constante às 'crianças' da escola mesmo para designar pessoas com 19, 20 anos. (MELETTI, 2006, p. 96)

Essa infantilização nos conteúdos é vista em várias reportagens, no caso de Rui, citado anteriormente, também notamos isto, pois mesmo já estando na $7^{\text {a }}$ série, ele aprendia sobre o dia da semana e estações do ano. Tendo em vista que a função da escola socialmente é a transmissão sistematizada dos conteúdos historicamente acumulados pela humanidade (SAVIANI, 2008), no caso dos alunos com deficiência, este objetivo não tem se cumprido.

No geral, podemos destacar que as situações de ensino às pessoas com deficiência e que são mostradas pela revista Nova Escola, denotam um descompasso no ensino dado a essas pessoas e aos demais alunos. Outra característica é a perpetuação de conteúdos infantilizados, mesmo para alunos que já estejam nos anos finais do ensino fundamental, mostrando uma hierarquia no ensino das matérias. 


\section{INTERAÇÕES NO INTERIOR DA ESCOLA}

Definimos como interações as situações em que os alunos com deficiência estão envolvidos com outros alunos ou outros profissionais que atuam na escola. Consideramos todas as partes da reportagem que se referissem a essa temática: texto, imagem e legenda.

Uma das reportagens fala sobre o trabalho desenvolvido numa escola particular que tem vários alunos com deficiência; conta os sucessos destes alunos junto com as suas turmas e se ampara na legislação ao denotar que a inclusão é um direito das pessoas com deficiência. Nesta reportagem, temos uma imagem de um aluno com deficiência junto de outro aluno não deficiente, em que a legenda é a seguinte: "Transformação radical: João não sabia conviver com outras crianças e hoje curte rap com seu melhor amigo, Renato" (CAVALCANTE, 2005, p. 45). Nessa legenda, Percebemos que João passou de uma criança que não se relacionava com os demais para agora ter vários amigos, mas apenas um amigo classificado como melhor. O tom de heroísmo, de uma vida transformada é muito forte. Percebemos neste trecho a ideia da deficiência relacionada à rebeldia e que a inserção na realidade escolar trouxe a superação na vida deste sujeito. Outro caso da mesma reportagem é de Nayara.

Desde que chegou à escola, em 1998, a família mantém um acompanhante para ajudar em sua higiene e na alimentação. No início foi difícil. Ela tirava a roupa, tinha medo de estranhos e era agressiva. Com o tempo e a dedicação dos professores, ela começou a desenvolver meios alternativos para reconhecer as pessoas, a voz o perfume ou algum acessório, como uma pulseira. É impressionante o carinho que Nayara tem pelos educadores e pelos colegas. Ela fala pouco, mas expressa o que sente pelo abraço. Do que ela mais gosta? Cantar. 'Nayara participa de todas as atividades e é muito querida', afirma a professora Simone Fernandes Saraiva, que deu aulas para Nayara do préa $4^{\text {a }}$ série. (CAVALCANTE, 2005, p. 44)

Com estes casos, percebemos que ocorreram mudanças significativas no comportamento dessas crianças, mas mais uma vez o destaque da revista está na superação de vida. Não que não existam mudanças com a inserção dessas crianças em ambientes de ensino regular, mas o tom utilizado pela revista vale-se do estereótipo da 
pessoa com deficiência como herói. A legenda da imagem da aluna Nayara nos leva a fazer mais algumas considerações: "Inclusão sem limites: Nayara tem um comprometimento mental severo, mas participa de todas as atividades" (CAVALCANTE, 2005, p. 44). A questão da negação da deficiência, por meio da compensação é clara na legenda. Haja vista, o abrandamento do comprometimento que ela tem devido à sua deficiência, compensando com outra qualidade, neste caso o fato de participar de todas as atividades (AMARAL, 1998).

Na mesma reportagem que tem o caso do Rui citado na temática de situação de ensino, encontramos outros exemplos. A reportagem inicia com o caso de dois jovens (Tiago e Fagner) que, segundo a revista, tiveram suas vidas transformadas após a inclusão. Traz a legislação que ampara a inclusão de pessoas com deficiência e um breve histórico da evolução do direito a essas pessoas. Explica também como deve ser o preparo com os professores e funcionários a partir da sensibilização mostrando as vantagens que os alunos com e sem deficiência podem ter com a inclusão. No caso do Tiago temos o seguinte:

\begin{abstract}
Tiago, de 11 anos, tem 30\% de visão apenas, além de hidrocefalia e dedinhos das mãos e dos pés grudados. Ele frequenta a E.M.E.F. Pedro de Oliveira, de Jundiaí (SP), em uma classe regular, junto com seus coleguinhas sem deficiência. Tiago aprende bem, está na média superior da classe, recebendo orientação pedagógica especial para deficientes visuais no Instituto Jundiaiense Luiz Braile e tem boa caligrafia e ortografia.

Tiago já foi um garoto revoltadíssimo, chutando as coisas, rasgando papéis. Não acreditava de jeito nenhum que um dia poderia frequentar uma escola regular. Hoje é um menino risonho, meigo e muito interessado em aprender. (JOVER, 1999, p. 8)
\end{abstract}

Este excerto traz à tona mais uma vez a questão da transformação do sujeito por meio da inclusão. Percebemos que o aluno em questão teve sua vida alterada, tomou nova feição, deixou de ser revoltado e indisciplinado para agora interessar-se por aprender. Relacionamos essa transformação a um dos estereótipos atribuídos às pessoas com deficiência, o estereótipo de herói. Amaral (1995) nos apresenta essa discussão, 
alegando que os estereótipos de vilão, herói e vítima, são muito utilizados pelas mídias no geral.

"Não acreditava de jeito nenhum que um dia poderia frequentar uma escola regular" (JOVER, 1999, p. 8), percebemos neste trecho que a afirmação é feita na $3^{\text {a }}$ pessoa do singular, "ele", ao sujeito não é dada a palavra, falam por ele. Desta maneira, é difícil dizer se realmente o Tiago acreditava que nunca frequentaria uma escola regular, ou se os outros é que não acreditavam nessa possibilidade.

“Hoje é um menino risonho, meigo e muito interessado em aprender" (JOVER, 1999, p. 8). Neste fragmento, a partir da análise de discurso, percebemos que o oposto ou o não dito no discurso tem muito significado. Neste caso, uma paráfrase deste trecho seria a seguinte: “Ontem era um menino choroso, ríspido e sem interesse em aprender”. Realizando essa paráfrase, notamos mais uma vez a relação da deficiência com a infelicidade. De acordo com Casado (1992), (apud D'ANTINO 2001, p.2), muitas instituições, a fim de conseguir recursos, utilizam-se desta "frequente associação da deficiência com a incapacidade total ou a infelicidade". Essa relação com a infelicidade é o que observamos neste trecho, ao dizer o que ele se tornou, subentende-se o que ele era e neste entendimento as suas características voltavam-se para características que não são bem-vindas.

Deste último trecho apresentado, podemos apreender mais uma ideia disseminada na revista e presente nas políticas, que é a escolarização em segundo plano. O destaque não está na importância dele aprender, mas em socializar.

Nesta mesma reportagem, ao tratar de outro aluno, Fagner, temos a seguinte descrição:

Fagner, também de 11 anos, é negro, pobre e totalmente cego. Estuda na mesma sala de Tiago. Ao entrar na escola, já tinha sido alfabetizado em braile de Instituto. Fagner é bastante inteligente e acompanha bem as aulas, embora não participe das atividades escritas porque não tem a máquina de braile (caríssima) que os deficientes visuais com recursos levam para a classe. Nas atividades orais ele é excelente. (JOVER, 1999, p. 8) 
Percebemos neste fragmento mais uma vez a estigmatização do indivíduo com deficiência, ocorrendo a anulação deste sujeito. Há um destaque para as características deste indivíduo que são permeadas de estigmas, pobre, negro e deficiente, numa forma de apelar para a sensibilização do leitor, mais especificamente o professor. A anulação deste aluno é explícita neste trecho, do modo como foi dito há um enaltecimento de todas as diferenças deste indivíduo. Pierucci (1999) nos mostra que essa é uma das ciladas das diferenças, pois da mesma forma que eu enalteço suas diferenças, corro o risco de estigmatizar mais ainda este indivíduo, é o que ocorre neste caso. E se comparamos com a forma que Fagner e Tiago foram descritos, notamos mais um silenciamento: Tiago não é descrito como branco, nem como sendo rico, apenas destacam a deficiência dele, ao contrário de Fagner que, como meio de sensibilizar mais ainda o leitor, destacam que ele é negro, pobre e sequer pode comprar a máquina de braile. E para compensar todos esses infortúnios de Fagner, destacam sua inteligência.

Merece um destaque a questão de associar a deficiência à infelicidade e a ênfase que é dada pela revista à rebeldia, à agressividade da pessoa com deficiência. Numa reportagem que tem por título "Chega de omissão" (Martins, 2009), que trata da violência sofrida por alunos com deficiência, percebemos que a revista indica estes atos de violência como bullying. Ou seja, quando a agressividade vem da pessoa com deficiência ela é a rebelde, a revoltada, a infeliz, afinal ela é deficiente. Entretanto, quando essa violência vem dos demais alunos para com o aluno com deficiência, essa é considerada bullying e o agressor não é considerado infeliz.

Nas reportagens em que havia um deficiente agressor, a sua interação com os outros alunos e a força de vontade da professora bastaram para que ele se transformasse num aluno com comportamentos adequados. Contudo, quando o deficiente está na posição de agredido, a revista traz várias intervenções pedagógicas significativas que podem ser realizadas para sanar essa agressividade. Ou seja, para os alunos com deficiência basta a tolerância e a boa vontade, já para os alunos "normais" são necessárias intervenções pedagógicas.

Garcia (2004) pontua em seus estudos que os discursos políticos de inclusão exprimem, dentre outros, a questão da solidariedade e do pertencimento. Quanto à solidariedade, "pode-se inferir, portanto, que os discursos que sustentam as políticas de 
inclusão cumprem o papel de difundir uma imagem solidária de sociedade, apaziguar tensões e obscurecer relações sociais de desigualdade" (GARCIA, 2004, p. 130). No que se refere ao pertencimento "é necessário desenvolver nas pessoas um sentimento de pertencimento à sociedade em que vivem, induzindo práticas adequadas a uma nova era econômica" (GARCIA, 2004, p. 130).

Ser solidário neste caso é aderir à causa da inclusão e notamos que as imagens das reportagens expressam muito bem isso. Temos um grande número de fotos que mostram todos, alunos e professores, felizes e sorridentes junto à pessoa com deficiência, conforme explicitaremos adiante.

$\mathrm{Na}$ capa de um das revistas que analisamos, fizemos alguns destaques para a imagem e o texto. Na imagem temos um "trenzinho" em que quem toma a frente é o aluno com deficiência física e percebemos que todas as crianças estão felizes ao redor deste aluno. A segunda criança que empurra a cadeira de rodas é uma menina negra que também chama a atenção do leitor por ser a única criança que olha para a câmera. Ao olhar para a capa, num primeiro momento nos chama atenção a criança na cadeira de rodas e depois a menina negra que empurra a cadeira de rodas.

No título da revista temos o seguinte: "A escola que é de todas as crianças", com um destaque na palavra todas em cor amarela, por coincidência (ou não?), amarela também é a cor do uniforme da escola que tem seu nome bem visível no aluno com deficiência física e é uma escola privada. No subtítulo: “Ao conviver com as diferenças, alunos e professores se tornam cidadãos solidários". Mais uma vez, um destaque para a questão da solidariedade tão solicitada nas nossas políticas.

Numa outra imagem, temos o aluno com deficiência sendo abraçado por outras crianças e a legenda que segue é a seguinte: “Grupo solidário: Junior está na $1^{\mathrm{a}}$ série da Escola Viva, em Cotia (SP). A paralisia cerebral e a cadeira de rodas não impedem que ele esteja com amigos, em uma turma regular (CAVALCANTE, 2005, p. 41)". A imagem e a legenda destacam a questão dele ter amigos, logo está colaborando para que as pessoas sejam solidárias. Outro conceito que podemos depreender nessas imagens, e que também é um dos fios que tecem as políticas de inclusão, é a questão da socialização. 
Em grande parte do nosso material empírico, temos a socialização como o principal objetivo da inclusão. Podemos perceber este conceito, não só através das imagens, como também pelos textos. A revista destaca o fato de o aluno ter amigos, brincar com eles e participar de situações comuns às demais crianças da mesma idade. $\mathrm{Na}$ mesma reportagem em que temos a história de Tiago e de Fagner, há também a história de Bruna, com paralisia cerebral, em que também podemos mostrar a questão da interação conforme o exemplo desta legenda: “Aline e Amanda, as amiguinhas do peito, ajudam Bruna a caminhar, estudam na mesma classe, batem papo, fazem fofoca e aprontam as maiores brincadeiras. Por sorte, Bruna pode falar à vontade" (JOVER, 1999, p. 11). Mais uma vez é explicita a negação da deficiência que é compensada no fato dela poder falar à vontade.

Podemos considerar que a revista sempre enfatiza a questão da interação como um ganho a mais que os alunos terão entre si ao incluírem as pessoas com deficiência. Termos como "todos vão lucrar" aparecem em vários artigos. O destaque que é dado é que a interação está sendo indicada como um benefício no sentido de que, ao incluir, proporcionaremos a adequação do sujeito. Há uma formatação deste indivíduo para uma condição de comportamento adequado ocorrendo, conforme Amaral (1998), uma negação da própria deficiência, no sentido de atenuá-la. Quanto menos deficiente ele for, melhor será. A adequação de comportamento do sujeito e a sua interação, mostram-se suficientes para a escola que é enaltecida por ter conseguido este feito.

\section{Considerações finais}

Neste trabalho, tivemos por objetivo analisar a disseminação das políticas de educação especial nas publicações da revista Nova Escola. Amparado nos preceitos da análise de discurso, pudemos apreender a forma como o discurso político está sendo disseminado. Bueno (2008) já nos mostrou em suas pesquisas que as políticas de inclusão escolar apresentam conceitos indefinidos com significados ambíguos que sofreram distorções de sentido ao serem traduzidas para o português. E é essa política com caráter lacunar que tem sido disseminada. E a disseminação que é feita pela revista Nova Escola, nos indica que não é necessário preencher essas lacunas; isso representa, de acordo com 
Orlandi (2003), um silenciamento. Este silenciamento mostra-se não só no que deixou de ser escrito, mas também na ausência das imagens, revelando diferentes formas de silenciamento.

A política parte do pressuposto de que a escola é perfeita, isenta de problemas e que só não está completa por não ter a pessoa com deficiência inserida nela (GARCIA, 2006). Salientando esta imperfeição da escola,Bourdieu (2003) nos mostra que a escola também não é preparada para a pobreza, mostrando-se excludente em sua essência. Dado o processo histórico, as pessoas com deficiência, juntamente com outros grupos marginalizados socialmente, foram relegadas aos processos de socialização. Ferraro (1999) complementa essa ideia dizendo que, quando tratamos da exclusão escolar, não podemos nos referir apenas aos que dela estão evadidos, pois existem dentro da escola também os excluídos.

Esta questão da normalização é disseminada com frequência, pois quando é trazida a história de algum aluno com deficiência, a superação desse aluno só é considerada quando ele deixa de apresentar comportamentos da deficiência, isto é, quando ele é tido como "menos deficiente", a situação melhora e todos ganham com isso. A adequação do comportamento é apresentada pela revista como suficiente para a entrada do aluno no ensino regular.

Ao analisar as reportagens, vemos que as condições não se alteram no período de tempo, as mesmas situações e o mesmo discurso encontrados nos anos iniciais à pesquisa, observamos também nos anos subsequentes.

Outro detalhe que vale ser ressaltado é o de que em nenhuma das reportagens há relatos das pessoas com deficiência, não é dada a voz ao deficiente. É sobre ele, mas não é com ele. Sobre isso, Meletti (2003, p. 2) afirma: “dar-lhe a palavra é uma forma de começar a romper com o estereótipo de que ela não é capaz de compreender o que a cerca, dando-lhe a possibilidade de se fazer ouvir sem ser através da voz do outro". Nas revistas, percebemos que esse estereótipo, de não dar voz ao deficiente, não é rompido, mas disseminado fortemente.

A escola não deixa de ser inclusiva só por não ter o aluno com deficiência, ao contrário disso, ela se mostra mais excludente justamente pela entrada desse alunado 
com deficiência. E com a política estruturada e disseminada dessa forma, só reforçamos mais essa ideia.

A nossa função enquanto pesquisadores é a de desvelar essas "contradições apresentadas pela pedagogia inclusiva, na medida em que essas puderem ser conhecidas em suas múltiplas relações com a base material capitalista" (BEZERRA, 2012, p.209). Ao entender que quando incluímos o aluno com deficiência estamos lhe dando um benefício, ao invés de um direito que lhe foi negado historicamente. E da forma que analisamos nas reportagens, esse direito continua sendo negado, por exemplo, quando a estes alunos oferece-se a tolerância, a boa vontade, conteúdos limitados, ao invés de ampliar as suas possibilidades de desenvolvimento por meio de um intenso trabalho pedagógico que respeite as diferenças. Sempre deixando claro que o direito não é a apenas estar na escola, mas se apropriar devidamente dos conteúdos que são trabalhados, garantindo o direito à escolarização efetiva.

\section{Referências}

AMARAL, Ligia Assumpção. Conhecendo a deficiência: em companhia de Hércules. São Paulo: Robe Editorial. 1995. 205 p.

AMARAL, Ligia Assumpção. Sobre crocodilos e avestruzes: falando de diferenças físicas, preconceitos e sua superação. In: AQUINO, J. G. (Org.) Diferenças e preconceitos na escola: alternativas teóricas e práticas. São Paulo: Summus. 1998, p. 11-32.

BAKHTIN, Mikhail Mikhailovich. Marxismo e filosofia da linguagem. 9 ed. São Paulo: Hucitec, 2002.

BEZERRA, Giovani Ferreira. Enquanto não brotam as flores vivas: crítica à pedagogia de inclusão. 2002,270 f. Dissertação (Mestrado em Educação) - Universidade Estadual do Mato Grosso do Sul, Nova Andradina, 2002. 
BOURDIEU, Pierre. Escritos de educação. In: Nogueira, M. A.; Catani, A. (Orgs.). Escritos de Educação. 5 ed. Petrópolis, Rio de Janeiro. Editora Vozes, 2003.

BRASIL. Ministério da Educação. Diretrizes nacionais para educação especial na educação básica/Secretaria de Educação Especial - MEC; SEESP, 2001. 79 p. Disponível em: < http://portal.mec.gov.br/seesp/arquivos/pdf/diretrizes.pdf >. Acesso em og de julho de 2015.

BRASIL. Lei 9.394, de 20 de dezembro de 1996: estabelece as diretrizes e bases da educação nacional. Brasília, 1996, Disponível em:

<http://www.planalto.gov.br/ccivil_03/leis/L9394.htm>Acesso em 09 de julho de 2015.

BRASIL. MEC/SEESP. Política nacional de educação especial na perspectiva da educação inclusiva. Documento elaborado pelo grupo de trabalho nomeado pela portaria ministerial n555/ 2007, entregue ao Ministro da Educação em 07 de janeiro de 2008. Disponível em http://portal.mec.gov.br/arquivos/pdf/politicaeducespecial.pdf. Acesso em: 09 de jul. de 2015.

BRASIL. Secretaria de Educação Fundamental. Parâmetros curriculares nacionais: adaptações curriculares. Estratégias para a educação de alunos com necessidades educacionais especiais. Brasília: MEC/SEF/SEESP, 1998. 62 p.

BUENO, José Geraldo Silveira. As políticas de inclusão escolar: uma prerrogativa da educação especial?. In: BUENO, J. G. S.; MENDES, G. M. L.; SANTOS, R. A. dos. (Orgs.). Deficiência e escolarização: novas perspectivas de análise. 1. ed. Araraquara/Brasília: Junqueira \& Marin/CAPES-PROESP,2008. v. 1, p. 43-63.

BUENO, José Geraldo Silveira. Educação infantil e educação especial: uma análise dos indicadores educacionais brasileiros. Contrapontos. Itajaí: UNIVALI, v. 11, p. 65-80, 2011.

BUENO Sinésio Ferraz. Semicultura e educação: uma análise crítica da revista Nova Escola. Rev. Bras. Educ., Rio de Janeiro, v. 12, n. 35, p. 300-307, ago. 2007. Disponível em: http://www.scielo.br/scielo.php?script=sci_arttext\&pid=S141324782007000200010\&lng=p t\&nrm=iso. Acesso em 10 de outubro de 2012.

CAVALCANTE, Meire. A escola que é de todas as crianças. Nova Escola, n. 182, p. 40-45, 2005 .

CAVALCANTE, Meire. Inclusão: a sociedade em busca de mais tolerância. Nova Escola, São Paulo, n. 196; p. 34-36, out. 2006.

CONFERÊNCIA MUNDIAL SOBRE NECESSIDADES EDUCACIONAIS ESPECIAIS. Declaração de Salamanca e linha de ação sobre necessidades educativas especiais. Local: editor, 1994. 
D’ANTINO, Maria Eloísa Famá. Deficiência e a mensagem reveladora da instituição especializada: dimensão imagética e textual. 2001, oof. Tese (Doutorado em Educação)Universidade de São Paulo, São Paulo, 2001.

FERRARO, Alceu Ravanelo. Diagnóstico da escolarização no Brasil. Revista Brasileira de Educação. v. 12,n.12, p.22-47, 1999.

GARCIA, Rosalba Maria Cardoso. Políticas públicas de inclusão: uma análise no campo da educação brasileira. 2004, 00 f. Tese) (Doutora do em Educação) - Universidade Federal de Santa Catarina, Florianópolis. 2004.

GARCIA, Rosalba Maria Cardoso. Políticas para a educação especial e as formas organizativas do trabalho pedagógico. Revista Brasileira de Educação Especial. v. 12, n.3, p.299-316, 2006.

GOÉS, Maria Cecília Rafael de. Relações entre desenvolvimento humano, deficiência e educação: contribuições da abordagem histórico-cultural. In: Oliveira, M. K.; Rego, T. C.; Souza, D. T. R.(Orgs.). Psicologia, educação e as temáticas da vida contemporânea. São Paulo: Moderna, 2002. P. 95-114.

JANNUZZI, Gilberta de Martino. A educação do deficiente no Brasil: dos primórdios ao início do século XXI. Campinas, São Paulo: Autores Associados. 2006.

JOVER, Ana. Inclusão: qualidade para todos. Nova Escola, n. 123, p. 8-17, 1999.

LEHER, Roberto. Educação no capitalismo dependente ou exclusão educacional. In: Mendonça, S. G. de L.; Silva, V. P. da; Miller, S. Marx, Gramsci e Vigotsky: aproximações. Araraquara, SP: Junqueira \& Marin, 2009. p. 223-252.

MARTINS, José de Souza. A sociedade vista do abismo: novos estudos sobre exclusão, pobreza e classes sociais. Petrópolis RJ: Vozes, 2002.

MARTINS, Ana Rita. Inclusão: chega de omissão. Nova Escola, n.228, p.78-81, 2009.

MATOS, Cleuza Maria Alves de. A forma-ação do discurso da/na revista Nova Escola. 2008, 148f. Tese (Doutorado em Estudos da Linguagem) - Universidade Estadual de Londrina, Londrina, 2008.

MELETTI, Silvia Márcia Ferreira. O relato oral como recurso metodológico de pesquisa em educação especial. In: Marquezine, M. C.; Almeida, M. A.; Omote, S. (Orgs.). Colóquios sobre pesquisa em educação especial. Londrina: Eduel, n. 01, p. 01-10, 2003.

MELETTI, Silvia Márcia Ferreira. Educação escolar da pessoa com deficiência mental em instituições de educação especial: da política à instituição concreta. 2006, oof. Tese (Doutorado em Educação) - Universidade de São Paulo, São Paulo, 2006. 
MELETTI, Silvia Márcia Ferreira. Projeto de Pesquisa: a escolarização de alunos com deficiência e rendimento escolar: uma análise dos indicadores educacionais em municípios brasileiros. Universidade Estadual de Londrina, Londrina, 2010.

MELETTI, Silvia Márcia Ferreira; BUENO, José Geraldo Silveira. Os indicadores educacionais como meio de avaliação das políticas de educação especial no Brasil 2000/2009. In: Bueno, J. G. S. (Org.). Educação especial brasileira: questões conceituais e de atualidade. São Paulo: EDUC, 2011. p. 159 -182.

ORLANDI, Eni Puccinelli. Análise de discurso: princípios e procedimentos. 5. ed. Campinas, SP: Pontes, 2003.

PIERUCCI, Antônio Flávio. Ciladas da diferença. 34. ed. São Paulo: USP, 1999.

RIPA, Roselaine. Nova Escola - "a revista de quem educa”: a fabricação de modelos ideais do ser professor. 2010, 219 f. Tese (Doutorado em Educação) - Universidade Federal de São Carlos, São Carlos, 2010.

RODRIGUES, Carlos. Inclusão: mente estimulada. Nova Escola, n.223, p. 92- 94, 2009.

SAVIANI, Dermeval. Pedagogia Histórico-crítica: primeiras aproximações. Campinas, SP: Autores Associados, 2008.

SILVA, Marcos; FEITOSA, Lucinéia dos Santos. Revista Nova Escola: legitimação de políticas educacionais e representação docente. Revista HISTEDBR on-line. Campinas, n.31. p. 183-198, set. 2008 .

SMOLKA, Ana Luiza Bustamante; GENTIL, Monica Salles. Duas revistas, três artigos, múltiplas vozes: um estudo sobre modos de dizer e posições sociais em textos para professores. Cad. CEDES on-line, v. 24, n. 63, p. 193-213, 2004.

VIGOTSKY, Lev Semyonovich. Fundamentos de defectologia. Havana: Pueblo y Educación, 1989 Obras Completas. v. 5. 